\title{
Foundation Phase teachers' understanding of attention deficit hyperactivity disorder at Johannesburg independent schools
}

\begin{tabular}{|c|c|}
\hline \multicolumn{2}{|c|}{$\begin{array}{l}\text { Authors: } \\
\text { Tamara H. Jaye } \mathrm{e}^{1} \\
\text { Cecil Levy }^{2} \\
\text { Jacob Majakwara }^{3} \\
\text { Sheri Hanson }\end{array}$} \\
\hline \multicolumn{2}{|c|}{$\begin{array}{l}\text { Affiliations: } \\
{ }^{1} \text { Department of Paediatrics } \\
\text { and Child Health, Health } \\
\text { Sciences School of Clinical } \\
\text { Medicine, University of } \\
\text { the Witwatersrand, } \\
\text { Johannesburg, South Africa }\end{array}$} \\
\hline \multicolumn{2}{|c|}{$\begin{array}{l}\text { Department of Nephrology, } \\
\text { Faculty of Paediatrics, Nelson } \\
\text { Mandela Children's Hospital, } \\
\text { Johannesburg, South Africa }\end{array}$} \\
\hline \multicolumn{2}{|c|}{$\begin{array}{l}{ }^{3} \text { School of Statistics and } \\
\text { Actuarial Science, Faculty } \\
\text { of Science, University of } \\
\text { the Witwatersrand, } \\
\text { Johannesburg, South Africa }\end{array}$} \\
\hline \multicolumn{2}{|c|}{$\begin{array}{l}{ }^{4} \text { Private Practice, } \\
\text { Johannesburg, South Africa }\end{array}$} \\
\hline \multicolumn{2}{|c|}{$\begin{array}{l}\text { Corresponding author: } \\
\text { Tamara Jaye, } \\
\text { tamara.jaye@gmail.com }\end{array}$} \\
\hline \multicolumn{2}{|c|}{$\begin{array}{l}\text { Received: } 13 \text { Nov. } 2019 \\
\text { Accepted: } 09 \text { Sept. } 2020 \\
\text { Published: } 08 \text { Dec. } 2020\end{array}$} \\
\hline \multicolumn{2}{|c|}{$\begin{array}{l}\text { How to cite this article: } \\
\text { Jaye, T.H., Levy, C., } \\
\text { Majakwara, J. \& Hanson, S., } \\
\text { 2020, 'Foundation Phase } \\
\text { teachers' understanding of } \\
\text { attention deficit hyperactivity } \\
\text { disorder at Johannesburg } \\
\text { independent schools', South } \\
\text { African Journal of Childhood } \\
\text { Education 10(1), a825. } \\
\text { https://doi.org/10.4102/ } \\
\text { sajce.v10i1.825 }\end{array}$} \\
\hline \multicolumn{2}{|l|}{ Read online: } \\
\hline 回最: & $\begin{array}{l}\text { Scan this QR } \\
\text { code with your } \\
\text { smart phone or } \\
\text { mobile device } \\
\text { to read online. }\end{array}$ \\
\hline
\end{tabular}

Background: Attention deficit hyperactivity (ADHD) disorder is a common childhood neurodevelopmental disorder. The symptoms of hyperactivity, impulsivity and inattention often become evident in a structured classroom setting. Teachers play a key role in identifying these features and referring these pupils for assessments.

Aim: This study investigated the understanding and perceptions of ADHD amongst Foundation Phase teachers at independent schools in Johannesburg.

Setting: This study was conducted at nine independent schools in the Johannesburg area.

Methods: A total of 95 teachers filled out a standardised questionnaire, the Knowledge of Attention Deficit Disorders Scale (KADDS), which looks at three aspects of ADHD, namely, associated features, symptoms and treatment. The teachers also answered several demographic questions such as their sex, age, level of education, knowledge of a person outside the school with ADHD and confidence to teach a child with ADHD. An informal directed discussion group was conducted, which comprised 32 teachers who had filled in the questionnaire. Open-ended questions were asked during the discussion group.

Results: The overall results were the highest obtained compared to similar previous studies. These teachers had a very good knowledge with regard to the symptoms of ADHD, they had a fair understanding about the treatment of ADHD and their knowledge about the associated features of ADHD was limited. Exposure to children with ADHD and higher number of ADHD workshops attended and ADHD articles read were beneficial to the teachers' overall knowledge about ADHD. Years of experience and the age of the teacher were not associated with a greater knowledge about ADHD.

Conclusion: Independent school Foundation Phase teachers displayed a good level of knowledge about ADHD. This knowledge was enhanced by continual ADHD education and exposure to children with ADHD.

Keywords: ADHD; Foundation Phase teachers; knowledge; perceptions; education.

\section{Introduction}

The classroom setting is often where symptoms of attention deficit hyperactivity disorder (ADHD) are most evident; it is therefore not uncommon for a teacher to notice this behaviour initially. Demands are put on the child to sit still at a desk for long periods of time, and the child with ADHD struggles to do this (Kos, Richdale \& Hay 2006:147).

Teachers play a major role in various aspects of the child with ADHD. The students' success at school is largely influenced by teachers who are willing and actively involved in working with them, in the framework of a system that supports identifying those with ADHD and providing necessary interventions for them (Pfiffner, Barkley \& Du Paul 2006:547). Teachers' attitudes towards a student with ADHD impact how other children in the classroom perceive that child (Gal, Schreur \& Engel-Yeger 2010:89).

Importantly, understanding and knowledge about ADHD have been shown to be related to teachers' attitudes and behaviour towards these children, highlighting how crucial the school environment is for the children with ADHD (Canu \& Mancil 2012:105; Pisecco, Huzinec \& Curtis 2001:413). Internationally, numerous research papers have examined teachers' knowledge about

Copyright: @ 2020. The Authors. Licensee: AOSIS. This work is licensed under the Creative Commons Attribution License. 
ADHD because of their proximity to these children, and the majority of the findings suggest that ADHD knowledge is limited (Sciutto et al. 2016:34). In South Africa, there is a paucity of studies examining teachers' perceptions and understanding of ADHD (Lazarus 2013), which similarly showed that some main aspects of ADHD were misperceived by these teachers (Kern et al. 2015; Lazarus 2013; Ntuli 2014; Sciutto et al. 2016:34; Topkin 2013).

To the best of the authors' knowledge, this is the first study in South Africa that examines Foundation Phase teachers in an independent school setting. We would expect results to differ from other studies at government schools because of various factors. Having a small number of learners per class in independent schools with a low learner to teacher ratio should provide the teacher in the independent school with the opportunity to notice a child with ADHD behaviour. There may be adequate ADHD training for teachers organised through these independent schools (Kellner, Houghton \& Douglas 2003:119), and as a result these teachers may be more aware of the features to look out for. The regular and ongoing relationship between parents and teachers in private schools may also give the teachers several opportunities to raise their concerns (Bayat, Louw \& Rena 2014:183).

The aim of this study was to evaluate Foundation Phase teachers' perceptions and understanding of ADHD in independent schools in Johannesburg with regard to general information about ADHD, how ADHD presents and is diagnosed and the treatment modalities that are available. We examined whether the level of knowledge was influenced by certain demographic factors, such as the level of education, length of teaching career, knowledge of ADHD people outside the school setting, number of ADHD courses attended and having taught children with ADHD in the past.

\section{Literature review}

According to Glass and Weger (2000:412), ADHD is one of the most publicised childhood conditions, with an associated increase in ADHD-like behaviour seen in the classroom (Efron 2017:825). This highlights the need to examine what teachers know about ADHD when it comes to the criteria of the disorder, its presentation, treatment options and long-term outcomes. Teachers inevitably play a key role in both the identification of the condition and intervention planning.

\section{Definition of attention deficit hyperactivity disorder}

Attention deficit hyperactivity disorder is a common neurodevelopmental disorder (Efron 2017:825; Efron, Sciberras \& Hassell 2008:187) comprising hyperactivity, inattention and impulsivity. It is pervasive across various settings and leads to functional impairment (Kos 2008). This pattern needs to persist for at least 6 months and interfere with the level of function or development (Kos 2008). Symptoms should be present before the age of 12 (Kos 2008). Three ADHD subtypes are the combined type, the predominantly inattentive type and the predominantly hyperactive-impulsive type (Kos 2008).

\section{Causes}

The expression of ADHD is a complicated sequential pathway that involves genetic, environmental and protective factors that each play their role in the disease development (Vizzini et al. 2019:521). Genetic studies have shown that there is a strong hereditary contribution towards the disorder (Faraone \& Larsson 2018:1). The heritable component is estimated to be close to $80 \%$ (Adams, Kirzinger \& Martinez 2013:1). Environmental factors have also been found to play a role in contributing to ADHD, which include perinatal factors (Training \& Bolat 2017:1645), maternal health (Instanes et al. 2017:452; Kosidou et al. 2017:651; Modesto et al. 2015:838), toxin exposure (Efron et al. 2017:187; Miller \& Hinshaw 2015:116; Thapar et al. 2013:3) and parenting styles (Kissgen \& Franke 2016:63; Norvilitis \& Fang 2005:413).

\section{Diagnosis}

The diagnosis of ADHD is clinical, based on set criteria defined by diagnostic classification systems (American Psychiatric Association 2013). Like other psychiatric conditions, in ADHD, there is no ancillary test that can be used to make a diagnosis (Dias et al. 2013:40). A comprehensive interview with the parents or caregivers of the child (Gualtieri \& Johnson 2005:44), teaching rating scales (Gualtieri \& Johnson 2005:44) and school reports (Gualtieri \& Johnson 2005:44) are helpful in making the diagnosis.

\section{Treatment}

The treatment of ADHD includes certain medication options as well as behavioural management techniques, with most clinical guidelines internationally suggesting a stepwise approach to ADHD management (Halperin, Bédard \& Curchack-Lichtin 2012:531; Sonuga-Barke et al. 2013:275). Non-pharmacological interventions have been recommended as the first-line therapy, and then, if there is little clinical improvement, medication should be initiated (Thapar et al. 2013:3). However, other guidelines recommend using an individualised approach, including pharmacotherapy, behavioural therapy and psychosocial interventions if necessary. Parental training is of particular importance in nursery school-aged children (Guideline 2011).

\section{Outcome}

If left untreated, the long-term prognosis of this disorder is poor, with ADHD sufferers not succeeding at school, in the workplace and in relationships (Mannuzza \& Klein 2000:711). There is an associated co-morbidity with mental health issues, such as depression (Fraser et al. 2018:243), anxiety, poor self-esteem (Dan \& Raz 2015:231; Mazzone et 
al. 2013:96) and drug-taking behaviour (Mannuzza \& Klein 2000:711).

\section{Teachers' role}

Teachers can play an ongoing and pivotal role in these children's lives in the areas of recognising features (Layton et al. 2018:2122), communicating with specialists (Sax \& Kautz 2003:171) and managing these children's behaviour in a classroom environment (Amod, Vorster \& Lazarus 2013:215; Ohan et al. 2008:436). As such it is vital that teachers have an in-depth understanding of ADHD. This should encompass knowledge about the causes of ADHD, which are multifactorial, with genetics interacting with environmental factors to produce the ADHD phenotype (Thapar et al. 2013:3; Vizzini et al. 2019:521).

Management of these children often involves medication (Bachmann et al. 2017:484; Taylor et al. 2004:i7); however, in a classroom setting, certain behavioural techniques are helpful to allow these children to reach a level where they could be able to perform well both academically and socially (Haggerty, McGlynn-Wright \& Klima 2013:229).

\section{Teachers' knowledge regarding attention deficit hyperactivity disorder}

Studies performed internationally and nationally on teachers' perceptions and knowledge of ADHD have shown that definite areas are lacking on this topic, and further training is suggested amongst Foundation Phase teachers (Perold, Louw \& Kleynhans 2010:457).

The majority of international studies about teachers' knowledge on ADHD suggests that it is limited (Sciutto et al. 2016:34). An important cause of this appears to be inadequate ADHD training (Perold et al. 2010:457). Furthermore, certain teacher demographics, such as teaching experience, have not consistently been found to affect overall ADHD knowledge amongst teachers (Kos 2008; Sciutto et al. 2016:34).

Limited knowledge about ADHD was observed in several international studies (Alkahtani 2013:963; Arora 2014:77; Kaur \& Nitakumari 2018:399), and many misconceptions exist about the disorder, mainly those surrounding the causes of ADHD and treatments available (Alkahtani 2013:963). The different types of ADHD were poorly understood (Kos 2008), and misperceptions surrounding non-medical interventions were common, such as the association between diet and ADHD symptoms (Kaur \& Nitakumari 2018:399). Many also believed that ADHD would be outgrown (Kaur \& Nitakumari 2018:399). Teachers have expressed that they would like more formal training (Jerome, Gordon \& Hustler 1994:563), and interventional ADHD training programmes for teachers have been observed to positively impact ADHD knowledge (Lasisi et al. 2017:15).

Very few studies have been conducted in South Africa examining teachers' perceptions and understanding of
ADHD. In 2010, the Knowledge of Attention Deficit Disorders Scale (KADDS) was used amongst teachers in Alexander township in Johannesburg (Lazarus 2013). Results showed that teachers lacked knowledge about ADHD, and some main aspects of ADHD were misperceived (Lazarus 2013). Perold et al. (2010) used the KADDS questionnaire amongst primary schoolteachers in the Cape Metropole and found that the majority were able to recognise ADHD behaviour; however, their knowledge relating to ADHD causes was limited (Perold et al. 2010:457). Perold et al. (2010:457) also found that the overall knowledge of ADHD was unrelated to the age of the teacher as well as years of teaching. A study using 200 teachers in the public schooling system in Kimberley (Topkin 2013) showed that the majority of teachers are knowledgeable about the symptoms and diagnosis of ADHD but less so about the general associated features and treatment (Kern et al. 2015:3042). A Johannesburg study included 15 schools, eight public and seven private schools, and consisted of both open-ended and closed-ended questions regarding ADHD (Kern et al. 2015:3042) and found that both sectors were similar in the areas of ADHD causes, incidence and treatment modalities. Ntuli (2014) conducted a study using a questionnaire on ADHD that was distributed to both mainstream and remedial schools in the Ekurheleni district in Johannesburg and found that negative attitudes about ADHD impacted these pupils' learning and educators' ADHD knowledge was limited.

\section{Research method and design Study design}

This study was a mixed-methods study. The first part of the study uses a relational and cross-sectional study design in the first two sections: (1) the demographics and (2) the questionnaire. Section A of the questionnaire considered the teachers' personal details such as sex, age, level of education and teaching experience. Teachers also needed to circle how many ADHD articles they had read as well as how many workshops on ADHD they had attended. They were required to quantify the number of children with ADHD they had taught during their career, if they knew anyone with ADHD outside school and if they felt confident to teach a child with ADHD. The second part was Section B, which was the KADDS questionnaire. The second part of the study was an informal discussion with several participants who had participated in the KADDS questionnaire.

\section{Setting}

This study took place in nine independent primary schools in Johannesburg from January to March 2019.

\section{Study population and sampling strategy}

The study population was teachers in the Foundation Phase of independent schools. A non-probability convenience sampling was performed with a sample size of 95 teachers. These educators were believed to have certain characteristics 
that would enable them to provide the relevant information required for the aim of this study. Foundation Phase educators were specifically selected for this study as this is often the schooling period when ADHD symptoms become evident (Pfiffner et al. 2006:547).

An informal discussion group, comprising 32 teachers, was conducted after the initial questionnaire. Open-ended questions were used in order to gain more insights into teachers' knowledge about ADHD. These teachers had all completed the KADDS questionnaire and consented to participate in the discussion group. The venue was the staff room at one of the participating schools. The duration of the group was approximately $1 \mathrm{~h}$. The chief investigator and one of the supervisors interviewed the candidates; the interview was audio-recorded and notes were taken. Open-ended questions relating to the pertinent themes of the questionnaire were explored.

\section{Measures}

The research tool used was the KADDS, a well-validated ADHD scale designed by Sciutto et al. (2016:34) in Massachusetts, which examines ADHD incidence rates, causes and appropriate interventions. The informal discussion group was conducted after the initial questionnaire using openended questions to gain more insights into teachers' knowledge about ADHD. This study used a qualitative research method with semi-structured questions.

\section{Data collection}

Twenty-four independent primary schools in Johannesburg were approached to participate in the study. The invitation to participate was extended via email, and those who did not respond were followed up by a phone call. Three schools declined to participate, 14 schools never responded to either email or telephone communication and nine schools agreed to participate in the study. The final sample consisted of 95 Foundation Phase teachers. A pilot study was implemented using three Foundation Phase teachers to ensure that the questionnaire was clear and easy to understand, as well as to confirm that the allocated time to fill out the questionnaire was appropriate.

\section{Data analysis}

Descriptive and inferential statistics were used to summarise the sample respondents and to test the objectives of this research study. The demographic characteristics of the respondents were illustrated using proportions. The comparison of proportions for correct answers obtained in each section of KADDS was tested using the large sample approximation test based on the chi-square distribution. The Marascuillo procedure was then used to identify the actual pair of proportions that differs significantly.

Pearson's correlation coefficient was used to measure the degree of linear association between demographic variables and sections of KADDS.

\section{Ethical consideration}

Ethical approval to conduct the study was obtained from the Human Research Ethics Committee (Medical) of the University of the Witwatersrand (certificate number: 180967).

Consent forms were provided to the school principals as well as to the participants who filled out the questionnaires. The aim of the study was clearly outlined, and anonymity was ensured. The participants understood that their names, their schools and their pupils would not appear in the research or subsequent publications. The consent form also clearly explained that participation was voluntary and that they can withdraw from the study at any time if they wished so.

The researcher was present when the forms were completed, and thus teachers had the opportunity to ask any further questions or clarify certain aspects of the study.

Regarding the informal discussion group, teachers who chose to participate were given a consent form to sign, agreeing to be part of the group, as well as a consent form that they agreed to be audio-recorded. As confidentiality is difficult to ensure in this scenario, the consent form had guidelines that asked participants to respect one another's privacy, not to share what was said during the group and allow a safe space for participants to express their views. These group rules were reiterated at the beginning of the informal discussion group.

\section{Results}

Table 1 shows the proportions in each category of a demographic variable. All the 95 teachers who participated in this study were women, with $80 \%$ of them aged between 30 and 59 years. In total, $60 \%$ of the teachers had read at least seven articles and $77 \%$ had attended at least three workshops. Only 3\% of the teachers were not confident about teaching children with ADHD, whilst 5\% did not know children with ADHD outside the school.

The KADDS questionnaire considered three different aspects of ADHD knowledge: (1) associated features, (2) symptoms and (3) treatment.

The average score for the questionnaire amongst this group of teachers was $63 \%$, with a standard deviation of $8.1 \%$.

\section{Associated features}

In this section on associated features, six of the questions were answered incorrectly by the group. On average, the proportion of questions answered correctly was 50\%, with a standard deviation of $12.5 \%$. Questions with poor scores included those pertaining to the genetic link of ADHD and its prevalence. Questions regarding the behaviour in a young child with ADHD and behaviour in novel situations, 
TABLE 1: Proportions in each demographic variable category.

\begin{tabular}{|c|c|}
\hline Demographic variable & Proportions in each category (\%) \\
\hline \multicolumn{2}{|l|}{ Age (years) } \\
\hline$<30$ & 6 \\
\hline 30-39 & 30 \\
\hline $40-49$ & 25 \\
\hline $50-59$ & 25 \\
\hline$>59$ & 14 \\
\hline \multicolumn{2}{|l|}{ Articles read } \\
\hline None & 0 \\
\hline $1-3$ & 3 \\
\hline $4-6$ & 21 \\
\hline $7-9$ & 24 \\
\hline$>9$ & 25 \\
\hline \multicolumn{2}{|l|}{ Workshops attended } \\
\hline None & 0 \\
\hline $1-2$ & 1 \\
\hline $3-4$ & 9 \\
\hline$>4$ & 90 \\
\hline \multicolumn{2}{|c|}{ Children with ADHD taught } \\
\hline None & 0 \\
\hline $1-2$ & 1 \\
\hline $3-5$ & 9 \\
\hline$>5$ & 90 \\
\hline \multicolumn{2}{|l|}{ Education level } \\
\hline Bachelor & 40 \\
\hline Graduate diploma & 37 \\
\hline Postgraduate & 23 \\
\hline \multicolumn{2}{|c|}{ Children with ADHD outside school } \\
\hline No & 5 \\
\hline Yes & 95 \\
\hline \multicolumn{2}{|c|}{ Confidence in teaching children with ADHD } \\
\hline No & 3 \\
\hline Yes & 97 \\
\hline
\end{tabular}

$A D H D$, attention deficit hyperactivity disorder.

as well as with different parenting figures, were answered incorrectly by most of these teachers. Strengths in this section included most teachers knowing that ADHD may be diagnosed in adulthood, and that childhood ADHD often persists into the adult years.

\section{Causes and prevalence of attention deficit hyperactivity disorder}

The genetic effect of ADHD was largely unknown in the group of participants, with only $41 \%$ (39 teachers) answering correctly. A teacher in the focus group who answered this correctly said:

'There's a large genetic component. We teach an ADHD child, and when we meet the parents it's obvious that one of them has ADHD too.' (Participant 5, 46 years old, female)

The vast majority of teachers were unaware of the latest statistics on ADHD in school-age children, with only 14 teachers $(14.7 \%)$ having the correct answer. The prevalence of ADHD differed between men and women, and 50 teachers were aware of this (52.6\%).

\section{Disease progression and associated co-morbidities}

In this category, $90(94.7 \%)$ teachers knew that it was possible for an adult to be diagnosed with ADHD. Of the 95 teachers, $57(60 \%)$ knew that ADHD symptoms are generally not outgrown, as evidenced in the following quote:

'By high school many have stopped their medication and are doing nicely, however many do need it long term from Grade 1 until matric.' (Participant 12, 62 years old, female)

Only $35.8 \%$ of participants (34 teachers) were aware that children with ADHD have higher rates of depression than those without ADHD.

\section{Behaviour in the classroom}

Of the 95 teachers, 88 (92.6\%) knew that an ADHD diagnosis does not make a child eligible for placement at a special school. Attention deficit hyperactivity disorder behaviour and a normal 4-year-old behaviour may appear to be the same, and 16 teachers $(16.8 \%)$ in this group were aware of this fact.

\section{Attention deficit hyperactivity disorder behaviour at home \\ Children without ADHD may exhibit ADHD symptoms if they come from home environments that are either chaotic or inadequate and 46 teachers $(48.4 \%)$ in this group answered this correctly. Only nine $(9.5 \%)$ teachers knew that these children were more compliant with their fathers compared to their mothers; 31 teachers marked this answer as 'I don't know'. Only $22(23.2 \%)$ of these teachers were aware that children with ADHD experience less problems in a novel situation.}

\section{Symptoms and diagnosis}

The results of this section showed that the majority of teachers had a very good understanding of the diagnosis and symptoms of ADHD. On average, the proportion of questions answered correctly was $77 \%$, with a standard deviation of $13.4 \%$.

Most of the questions in this section were answered correctly by the majority of the teachers, with $11 \%$ of teachers getting all the answers correct. Teachers were aware that certain features were required to make a diagnosis, and they understood that symptoms need to occur in different settings, as well as the possibility of an adult diagnosis being made. They also knew about the poor effect of ADHD on a child's self-esteem.

\section{Diagnosis of attention deficit hyperactivity disorder}

Ninety teachers (94.7\%) were aware about the classification of ADHD into two clusters. To diagnose an ADHD, symptoms need to be present in two or more settings and 77 teachers $(81 \%)$ knew this. Fifty-three teachers (56\%) knew that ADHD symptoms do not need to be present before the age of 7 years.

Inattentive and hyperactive symptoms of attention deficit hyperactivity disorder

Eighty-four teachers (88\%) knew that children who have ADHD are distracted by extraneous stimuli, as clear in the following quote: 
'When they're on their own with no distractions, they can sit for hours and do puzzles or Lego. In a busy classroom they're often unable to do the work. They'll hear a sparrow outside the class and think "What's that?" and forget about their class work.' (Participant 3, 51 years old, female)

The majority of teachers (93.7\%) were aware that children squirming in their seats is a feature of ADHD. An ADHD diagnosis means that children are often disorganised when it comes to tasks and activities, and 91 teachers $(95.8 \%)$ knew this.

\section{Symptoms that are not associated with an attention deficit hyperactivity disorder diagnosis}

Eighty-one teachers (85\%) were aware that being cruel to others is not a feature of ADHD. Children with a diagnosis of ADHD do not steal or destroy other people's things, and 58 teachers $(61 \%)$ knew this.

Sixty-four teachers (67.4\%) knew that a good self-esteem is not common with children with ADHD:

'Their self-esteem often improves with the medication. It is very undermining for the child when they can't perform on par with their colleagues.' (Participant 12, 62 years old, female)

\section{Treatment}

In this section on treatment, on average, $63 \%$ teachers, with a standard deviation of $13.6 \%$, answered the questions correctly. Only one teacher got all the answers correct.

The majority of this group of teachers were unaware of the role of anti-depressant medication in ADHD treatment, and that electroconvulsive therapy (ECT) has no place in ADHD treatment. Most teachers in this group felt that sugar and colourants influence ADHD behaviour negatively. They were also unaware of the primary elements of ADHD being addressed with behavioural therapy.

\section{Behavioural and non-medical management of attention deficit hyperactivity disorder}

Behavioural interventions for ADHD do not primarily focus on inattention and 42 teachers $(44.2 \%)$ in this group were aware of this fact. Only 28 teachers (28.5\%) knew that reducing sugar or food additives could not reduce ADHD symptoms. When asked about whether sugar affects the behaviour, one teacher in the focus group answered:

'Yes definitely! Our school tuckshop has limited sweets. With the younger kids we try [to] implement that sweets are rather eaten at second break.' (Participant 7, 36 years old, female)

\section{Pharmacotherapy for attention deficit hyperactivity disorder}

Only 25 teachers (26\%) knew that anti-depressant medication may help in reducing ADHD symptoms. Thirty teachers $(31.6 \%)$ were correct in answering that ECT is not effective for severe cases of ADHD. Sixty-three teachers in this group were not sure about the answer and answered 'I don't know'.

\section{Training}

Questions 37, 38 and 39 of the KADDS were included for training purposes, and they were added to the questionnaire and were not categorised. Fifty-one teachers (53.7\%) knew that prolonged stimulant use does not lead to an increased addiction in adulthood. Thirty-seven teachers said they did not know the answer:

'Parents often mention they're concerned that the medication may make their child turn into a drug addict. However, the opposite is true.' (Participant 2, 32 years old, female)

Less than half (44.2\%) of the teachers knew that if a child responds to stimulant medication, the child does not necessarily have ADHD. A small percentage (33.7\%) of teachers knew that inflexibility to certain routines and rituals is not a feature generally displayed by those with ADHD.

\section{Inference}

The proportions of correct answers for each section of KADDS varied from $50 \%$ to $77 \%$, and there is a need to establish statistically whether the proportions are different for each section. The chi-squared test was carried out to compare the three sections, and the test statistic value obtained was 174.08 at two degrees of freedom, with a probability value ( $p$-value) of approximately zero. This shows that at least one of the proportions is highly significantly different from others.

To establish which proportions are different, a Marascuillo procedure was used. The $p$-value obtained for all the three pairwise comparisons was approximately zero, showing that the proportions of questions answered correctly for the sections of KADDS were highly significantly different.

To establish whether knowledge of sections of KADDS was influenced by certain demographic factors, Pearson's correlation coefficient was calculated for each pair (each section of KADDS with each demographic variable), and the results are presented in Table 2. Note that the number of children taught with ADHD has a low positive linear association with each section of KADDS. The number of articles read and treatment have a Pearson's correlation coefficient of 0.37 , showing that the more articles the teachers read, the higher the chance of knowing the treatment. Generally, the number of articles read, the number of workshops attended and the number of children with

TABLE 2: Pearson's correlation coefficient for demographic variable with Knowledge of Attention Deficit Disorders Scale section.

\begin{tabular}{lccc}
\hline Demographic variable & \multicolumn{3}{c}{ KADDS section } \\
\cline { 2 - 4 } & Associated features & Symptoms & Treatment \\
\hline Age & -0.05 & 0.02 & 0.13 \\
Experience & -0.03 & 0.00 & 0.02 \\
Articles read & 0.14 & -0.02 & 0.37 \\
Workshops & 0.10 & 0.03 & 0.23 \\
Children with ADHD taught & 0.20 & 0.19 & 0.27 \\
Education & 0.08 & 0.07 & 0.01 \\
\hline
\end{tabular}

ADHD, attention deficit hyperactivity disorder; KADDS, Knowledge of Attention Deficit Disorders Scale. 
ADHD taught have a weak positive linear association with the treatment section of KADDS. Age, experience and education level seem to have a very little to no linear association with each of the KADDS section.

\section{Discussion}

\section{Overall score}

The results of the administered KADDS questionnaire amongst the independent schools Foundation Phase teachers in Gauteng revealed that this group did particularly well compared to other groups that have participated in the previous studies using the KADDS. The results of this study showed that the educators' overall percentage score of correct responses was $63 \%$, which means that the respondents answered $63 \%$ of all the 39 KADDS items correctly. This is one of the highest scores reported internationally where the KADDS tool was used. These results are very similar to those obtained by Kos (2008), who reported that $61 \%$ of the items on the KADDS were answered correctly by the Melbourne educators. The high scores obtained in these two studies are most likely the result of the ongoing training and workshops that are being offered to these educators. In contrast, Lazarus' (2013) study that involved 100 teachers from Alexandra township in Johannesburg had an overall score of 35\%.

\section{Subset scores}

When making comparisons between the different subsets used in studies that used the KADDS, the current study found that the section on symptoms answered the best, with a score of $76.7 \%$; however, the treatment section's overall score was only $63 \%$, and the associated features was the most poorly answered section, with a score of $50 \%$. This is in line with several other studies that also showed that teachers knew more about ADHD symptoms than treatment and associated features (Topkin 2013).

\section{Knowledge about associated features of attention deficit hyperactivity disorder}

In the associated features section, most independent schoolteachers (two-thirds) knew that children with ADHD have low selfesteems. The prevalence of ADHD was answered very poorly by the independent schoolteachers, which was echoed by the low results found by the Alexandra teachers, where only $4 \%$ had the correct answer (Lazarus 2013), and Perold et al.'s (2010:457) group of teachers. Reasons for this incorrect answer may be because of teachers' feeling that the prevalence of ADHD is in fact higher. Attention deficit hyperactivity disorder - like features such as inactivity or hyperactive symptoms may be present in certain children; however, for a diagnosis to be made, one needs to have six features in either the impulsive category or the inattentive category. If fewer criteria are met, the diagnosis of ADHD cannot be made.

\section{Genetic role in attention deficit hyperactivity disorder}

In total, $41 \%$ of the independent schoolteachers were unaware that ADHD has a genetic link. Interestingly, in a sample of teachers studied by Glass and Wegner (2000:412), about $80 \%$ of teachers were aware that ADHD was a biological abnormality; however, $11 \%$ believed that it was the result of environmental factors.

\section{Behaviour in novel situations}

Children with ADHD seem to have better behaviour in novel situations, and many independent schoolteachers did not know this. This seems to be true of the other South African studies too (Lazarus 2013; Perold et al. 2010:457). Behavioural difficulties in children with ADHD are often not as evident in novel situations, and this is especially the case when the tasks at hand are interesting, easy and repetitive (Greene 1995:81).

\section{Attention deficit hyperactivity disorder gender prevalence}

Most independent schoolteachers knew that the prevalence of ADHD differs between boys and girls, with just over half the group of independent teachers getting the correct answer. In comparison, only 33\% of the teachers in Lazarus' (2013) study were aware of this.

\section{Attention deficit hyperactivity disorder behaviour in different settings}

Two-thirds of the independent schoolteachers in this study answered that ADHD symptoms are more obvious in the classroom than in a free play environment. This question was answered relatively well in Lazarus' (2013), Perold et al.'s (2010:457) and Topkin's (2013) studies. Teachers seem to be aware that a more structured environment is difficult for these children, and their ADHD features are thus more obvious in the classroom (Kos 2008).

\section{Symptoms}

The overall score for the symptoms section was $80 \%$ for the independent schoolteachers, the section that was answered best in the study. Several other studies support this concept that educators are knowledgeable in this particular area of ADHD. This was seen with Lazarus' (2013) and Perold et al.'s (2010:457) study that also showed the treatment section as having the highest overall score (Kern et al. 2015:3042).

\section{Attention deficit hyperactivity disorder behaviour}

The current study showed that the vast majority of independent schoolteachers were well aware that being unable to sit still was an ADHD feature, and once again most of the independent teachers (more than $90 \%$ in this case) knew about the different clusters of ADHD. These behavioural symptoms are well known to teachers, with both local and international studies showing similar results (Kern et al. 2015:3042; Topkin, Roman \& Mwaba 2015:1). More than $75 \%$ of Perold et al.'s (2010:457) respondents were able to identify the symptoms of distractibility, fidgeting and disorganisation, as well as of the primary clusters of symptoms of ADHD. The majority of independent schoolteachers were aware that disorganised behaviour is part of ADHD. This was also well answered by the 
Alexandra township teachers, with most of them providing the correct answer (Lazarus 2013).

\section{Treatment}

The independent schoolteachers scored $63 \%$ overall in the treatment section. This section was answered better than the associated features section, however the symptoms section was answered the best out of all 3 the sections on the questionnaire.

\section{Parenting and attention deficit hyperactivity disorder}

The vast majority of independent schoolteachers were aware that a certain parenting style did not cause ADHD. In a previous study conducted in Johannesburg including private and public schoolteachers, $42 \%$ of the teachers indicated that they felt 'inadequate' parenting may be the cause of ADHD (Kern et al. 2015). However, research has not found poor parenting to be an aetiological cause; rather it may exacerbate the condition (Nel, Nel \& Hugo 2013).

\section{Role of antidepressants in treatment and administering medication}

Only a quarter of the independent schoolteachers answered correctly that anti-depressants may be used to treat ADHD (Otasowie et al. 2014). Less than half of the Alexandra township teachers got this answer correct (Lazarus 2013). The focus group of independent schoolteachers highlighted some gaps in teachers' knowledge regarding medication. This included how the medication can be administered, which capsules may be opened and which side effects are caused by the medication versus those pre-existing conditions that the medicine may exacerbate. This information, possibly incorrect, may be passed on to the parents (Kos, Richdale \& Hay 2006:147).

\section{Role of sugar and preservatives in attention deficit hyperactivity disorder behaviour}

The effect of sugar and preservatives in ADHD behaviour was answered correctly by only less than one-third of the independent schoolteachers. In the Alexandra study, only $7 \%$ answered this correctly (Lazarus 2013). Various international studies have found an association between sugar and hyperactivity (Jerome et al. 1994:563; Perold et al. 2010:457). Across countries, up to $40 \%$ of the teachers felt that sugar elimination diets are effective in reducing ADHD-type behaviour; this belief was particularly high amongst South African and German teachers. This is one of the most commonly held misperceptions about ADHD (Sciutto et al. 2016:34). This has not been supported by the current body of scientific evidence, and teachers' views may be incorrectly shared with parents (DiBattista et al. 2013:275). A large metaanalysis showed no statistical significance when specific elimination diets were implemented or food colourants were reduced (Sonuga-Barke et al. 2013:275).

\section{The role of electroconvulsive therapy}

Electroconvulsive therapy as a form of ADHD was answered correctly by only one-third of the independent schoolteachers. The majority of teachers answered 'I don't know'. Electroconvulsive has rarely been used in ADHD, and this has been used to treat co-morbid conditions such as severe depression (Reichenberg \& Seligman 2016). Similarly, in the Kimberley study, $74 \%$ of teachers answered 'I don't know' (Topkin et al. 2015:1). Vereb found that the more knowledge an educator has about a particular treatment or behavioural intervention, the more likely he or she would consider the intervention to be acceptable, and thus encourage its usage (Vereb \& DiPerna 2004:421). Limited knowledge as well as misperceptions surrounding ADHD treatment amongst educators is the cause for concern as expressed by Efron et al. (2008:187), as teachers play a key role in identifying, managing and treating ADHD.

\section{Attention deficit hyperactivity disorder medication and substance abuse}

The role of stimulant medication in later substance abuse was answered correctly by only half of the independent schoolteachers, with a large proportion answering that they did not know the answer. The concern of teachers having a misunderstanding about ADHD medication and the perception that it may lead to drug abuse behaviour may cause teachers to offer incorrect advice to families. For example, teachers may suggest to parents that a child should try an exclusionary diet to manage symptoms because ADHD medication may lead to harmful behaviour (Sciutto et al. 2016:34).

\section{Autism spectrum disorder and attention deficit hyperactivity disorder}

The question regarding inflexibility and adherence to rituals was answered correctly by only one-third of the independent schoolteachers. These are symptoms of autism spectrum disorder. If these symptoms are mistaken as ADHD, this may have ramifications when it comes to offering advice to parents and managing these children in the classroom (Efron 2017:825). Also, important measures necessary to manage ASD behaviour may be delayed. Sciutto et al. (2016:34) suggested that any behaviour that is viewed as different or unacceptable may possibly be considered to be ADHD by some teachers.

\section{Factors influencing teachers' knowledge about attention deficit hyperactivity disorder}

\section{Confidence in teaching children with attention deficit hyperactivity disorder}

In this study, only four teachers felt unconfident to teach children with ADHD. Two of these teachers were over 50 years old and had taught for many years, whilst the other two teachers were far younger and had less teaching experience. All these four teachers passed the questionnaire overall. This suggests that experience may not always instil a sense of confidence; however, other studies have shown that an increased level of confidence is associated with more knowledge about ADHD (Sciutto et al. 2016:34).

\section{Years of teaching}

Previous studies have found that the longer one teaches for, the more knowledge one has about ADHD, as was the 
case with Canadian teachers (Jerome et al. 1994:563) and United States primary schoolteachers (Sciutto et al. 2016:34). The current study found no association between years of teaching and knowledge of ADHD. This was also found with other research (Jerome et al. 1994:563; Kos et al. 2006:147; Sciutto et al. 2016:34). This is an interesting finding as it suggests that experience may not be adequate when it comes to noticing ADHD symptoms and being knowledgeable about the condition.

\section{Exposure to attention deficit hyperactivity disorder children}

Better knowledge of ADHD has been linked to more exposure of children with ADHD (Kos et al. 2006:147; Perold et al. 2010:457). This study found that teachers' knowledge of ADHD in all three categories being examined - associated features, symptoms and treatment - were superior when they had taught children with ADHD as opposed to those who had not previously taught children with ADHD. Teachers who reported having prior exposure to children with ADHD had their total knowledge scores far higher than teachers without exposure to pupils with ADHD (Sciutto et al. 2016:34).

\section{Training}

More training has been associated with better knowledge about ADH (Kos et al. 2006:147; Perold et al. 2010:457; West et al. 2005:192). The current study showed that teachers who attended workshops had better knowledge of ADHD symptoms as opposed to teachers who had not attended any workshops. This is in line with international findings (Lasisi et al. 2017:15). This current research also found an association between workshop attendance and ADHD articles read.

\section{Reading attention deficit hyperactivity disorder articles}

The current study showed significant differences in detecting ADHD symptoms by those teachers who had read more ADHD articles as opposed to those who had read fewer articles. Sciutto et al. (2016:34) also found a correlation between reading professional literature on ADHD and the level of knowledge, and this finding was consistent with Perold et al.'s (2010:457) research too.

\section{Knowledge of someone with attention deficit hyperactivity disorder}

Sciutto et al.'s (2016:34) study found an association between having a family member or friend with ADHD and greater knowledge of ADHD in terms of symptoms, diagnosis and treatment options. This cohort of teachers had more knowledge about ADHD treatment when they expressed that they knew someone outside the classroom who had ADHD.

\section{Limitations of the study}

Of the 24 schools that were approached, only nine agreed to participate. This begs to the question of why those schools refused to participate. Was it simply because the principals in these schools felt the teachers were too busy and did not have the time to participate? Or perhaps those schools did not have regular ADHD training and the results would show this? Did those schools that participated have a greater interest in the topic, and as such encourage their staff to keep up to date on the subject? Furthermore, as only nine schools participated in this study, a possible limitation may be that this sample is not representative of all independent schools in the province.

Participation in this study was voluntary. A purposive, nonprobability sampling method was used. This sample does not fully represent the population of independent school Foundation Phase teachers as those who responded had chosen to do so. Also, all the participants in this study were women and only schools in a certain geographic location were selected for this research, which rendered this study as both small and narrow. Thus, generalisability of the findings was a concern, and widespread conclusions about independent school Foundation Phase teachers' knowledge regarding ADHD may not be possible from this study.

The KADDS was designed in 2000. Some developments in ADHD research have subsequently resulted in new knowledge regarding the topic, as well as guideline changes. Whilst the Diagnostic and Statistical Manual of Mental Disorders (DSM)-4 made an ADHD diagnosis by age 7 (Willcutt 2012:419), the DSM-5 has now broadened to include children aged up to 12 years (American Psychological Association 2013). The answer regarding age of diagnosis would have been true if the KADDS was administered with DSM-4; however, it is now false as the age has changed in the $D S M-5$. Furthermore, the answer regarding the features of autism also depends on which DSM is used. The DSM-4 clearly stated that an ADHD diagnosis could not be made if autism was present (Epstein \& Loren 2013:455). The new DSM-5 allows both these diagnoses to co-exist in one patient, and therefore the answer is not as clear as when the previous DSM was used.

The question regarding behaviour in children aged 4 years is complex. The number of pre-school children with an ADHD diagnosis has doubled over the past 10 years, proving that there is a possibility that ADHD-type behaviour can be observed in very young children and it differs from their neuro-atypical peers. This is seen with the American Academy of Paediatrics (AAP) including this very young group in their stratification system for managing young children with ADHD (Fiks et al. 2016).

Workshop attendance was a variable that was used with the purpose of showing that workshops are associated with better knowledge of ADHD. Sciutto et al.'s (2016:34) cross-national study highlighted two issues by using this as a variable to illustrate the level of knowledge.

Firstly, the specific nature of the training programmes was not explored at all. Secondly, a training programme may not address certain key aspects. By doing this, it may prove to be a less effective programme, or potentially even inadvertently allow certain misconceptions to be strengthened as inaccurate 
beliefs held by participants are not addressed or rectified (Sciutto et al. 2016:34). Training programmes may skew the relevance of certain concepts, with those topics that are not fully covered being understood to be somewhat less important (Sciutto et al. 2016:34).

\section{Recommendations for future research}

A follow-up study could entail using independent Foundation Phase teachers once again. However, unlike the current study, a measurement could be instituted and implemented before and after ADHD training. A programme focusing on the main areas of ADHD that are pertinent to teachers could be developed.

\section{Conclusion}

Overall, the independent schoolteachers in this study scored very well. This is in comparison to other bodies of research, both locally and internationally, which have used the KADDS.

The teachers in this study had very good knowledge with regard to the symptoms of ADHD, they had a fair understanding about the treatment of ADHD and their knowledge about the associated features of ADHD was limited. The proportion of knowledge of each section of KADDS was significantly different from any other KADDS section.

Exposure to children with ADHD resulted in teachers having the most knowledge in terms of recognising symptoms of ADHD, being aware about features that are associated with ADHD, and the medication and behavioural interventions that are available and effective.

Years of experience was not associated with a greater knowledge about ADHD.

Knowledge of a family member or friend outside the school with ADHD was found to be advantageous to this group of teachers. This study found that their understanding of the available treatments for ADHD was better compared to teachers who had no relationship with people with ADHD.

Workshops about ADHD and reading material related to ADHD are beneficial to teachers' overall knowledge of the condition as compared to those who had read fewer articles and attended less workshops. An association between workshop attendance and ADHD articles read was found.

As ADHD prevalence is at its highest, and children are often being diagnosed in the Foundation Phase because of the increased demand to sit attentively for longer periods of time, regular workshops should be available for Foundation Phase teachers. This study, as with other bodies of research, has shown that ongoing training is effective in improving teachers' understanding of the condition, recognising ADHD symptoms as well as providing tools for managing these children in the classroom.

\section{Acknowledgements Competing interests}

The authors have declared that no competing interests exist.

\section{Authors' contributions}

All authors contributed equally to this work.

\section{Funding information}

This research received no specific grant from any funding agency in the public, commercial or non-for-profit sectors.

\section{Data availability statement}

The authors confirm that the data supporting the findings of this study are available within the article.

\section{Disclaimer}

The views and opinions expressed in this article are those of the authors and do not necessarily reflect the official policy or position of any affiliated agency of the authors.

\section{References}

Adams, P.F., Kirzinger, W.K. \& Martinez, M., 2013, 'Summary health statistics for the U.S. population: National Health Interview Survey, 2012', Vital and Health Statistics 259(1), 1-95. https://doi.org/10.1016/0160-7979(78)90117-0

Alkahtani, K.D.F., 2013, 'Teachers' knowledge and misconceptions of attention deficit/ hyperactivity disorder', Psychology 4(12), 963. https://doi.org/10.4236/ psych.2013.412139

American Psychiatric Association, 2013, Diagnostic and statistical manual of mental disorders (DSM-5 $\left.{ }^{\circledR}\right)$, American Psychiatric Publishing, Washington, DC

Amod, Z., Vorster, A. \& Lazarus, K., 2013, 'Attention-deficit/hyperactivity disorder (ADHD) as a barrier to learning and development within the South African context: The perspective of teachers', in S. Banerjee (ed.), Attention deficit hyperactivity disorder in children and adolescents, Intec Rijeka, Croatia, pp. 215-241

Arora, V.K., 2014, 'Concepts and misperception of school teachers regarding attention deficit hyperactivity disorder (ADHD)', Training \& Development Journal 5(2), 77-81.

Bachmann, C.J., Wijlaars, L.P., Kalverdijk, L.J., Burcu, M., Glaeske, G., Schuiling-Veninga, C.C.M. et al., 2017, 'Trends in ADHD medication use in children and adolescents in C.C.M. et al., 2017, 'Trends in ADHD medication use in children and adolescents in
five western countries, 2005-2012', European Neuropsychopharmacology 27(5), 484-493. https://doi.org/10.1016/j.euroneuro.2017.03.002

Bayat, A., Louw, W. \& Rena, R., 2014, 'The impact of socio-economic factors on the performance of selected high school learners in the Western Cape Province, performance of selected high school learners in the Western Cape Province, South Africa', Journal of Hum

Canu, W.H. \& Mancil, E.B., 2012, 'An examination of teacher trainees' knowledge of attention-deficit/hyperactivity disorder', School Mental Health 4(2), 105-114. https://doi.org/10.1007/s12310-012-9071-3

Dan, O. \& Raz, S., 2015, 'The relationships among ADHD, self-esteem, and test anxiety in young adults', Journal of Attention Disorders 19(3), 231-239. https://doi. org/10.1177/1087054712454571

Dias, T.G.C., Kieling, C., Graeff-Martins, A.S., Moriyama, T.S., Rohde, L.A. \& Polanczyk, G.V., 2013, 'Developments and challenges in the diagnosis and treatment of ADHD', Revista Brasileira de Psiquiatria 35(Suppl. 1), 40-50. https://doi. org/10.1590/1516-4446-2013-S103

DiBattista, D. \& Shepherd, M.-L., 1993, 'Primary school teachers' beliefs and advice to parents concerning sugar consumption and activity in children', Psychological Reports 72(1), 47-55. https://doi.org/10.2466/pr0.1993.72.1.47

Efron, D., 2017, 'The role of schools in the diagnosis of ADHD', The Lancet Psychiatry 4(11), 825-826. https://doi.org/10.1016/S2215-0366(17)30406-6

Efron, D., Sciberras, E. \& Hassell, P., 2008, 'Are schools meeting the needs of students with ADHD?', Australasian Journal of Special Education 32(2), 187-198. https:// doi.org/10.1017/S1030011200025847

Epstein, J.N. \& Loren, R.E.A., 2013, 'Changes in the definition of ADHD in DSM-5: Subtle but important', Neuropsychiatry 3(5), 455. https://doi.org/10.2217/npy.13.59

Faraone, S.V. \& Larsson, H., 2018, 'Genetics of attention deficit hyperactivity disorder', Molecular Psychiatry 24(4), 562-575. https://doi.org/10.1038/s41380-018-0070-0

Fiks, A.G., Ross, M.E., Mayne, S.L., Song, L., Liu, W., Steffes, J. et al., 2016, 'Preschool ADHD diagnosis and stimulant use before and after the 2011 AAP Practice Guideline', Pediatrics 138(6), e20162025. https://doi.org/10.1542/peds.2016-2025 
Fraser, A., Cooper, M., Agha, S.S., Collishaw, S., Rice, F., Thapar, A. et al., 2018, 'The presentation of depression symptoms in attention-deficit/hyperactivity disorder: Comparing child and parent reports', Child and Adolescent Mental Health 23(3), 243-250. https://doi.org/10.1111/camh.12253

Gal, E., Schreur, N. \& Engel-Yeger, B., 2010, 'Inclusion of children with disabilities: Teachers attitudes and requirements for environmental accommodations', International Journal of Special Education 25(2), 89. https://doi.org/EJ890588

Glass, C.S. \& Wegar, K., 2000, 'Teacher perceptions of the incidence and management of attention deficit hyperactivity disorder', Education 121(2), 412-420.

Greene, R.W., 1995, 'Students with ADHD in school classrooms: Teacher factors related to compatibility, assessment, and intervention', School Psychology Review 24(1), 81-93. https://doi.org/10.1080/02796015.1995.12085753

Gualtieri, C.T. \& Johnson, L.G., 2005, 'ADHD: Is objective diagnosis possible?', Psychiatry (Edgmont) 2(11), 44.

Guideline, C.P., 2011, 'ADHD: Clinical practice guideline for the diagnosis, evaluation, and treatment of attention-deficit/hyperactivity disorder in children and adolescents', Pediatrics 128(5), 1007-1022. https://doi.org/10.1542/ peds.2011-2654

Haggerty, K.P., McGlynn-Wright, A. \& Klima, T., 2013, 'Promising parentin programmes for reducing adolescent problem behaviours', Journal of Children's Services 8(4), 229-243. https://doi.org/10.1108/JCS-04-2013-0016

Halperin, J.M., Bédard, A.-C.V. \& Curchack-Lichtin, J.T., 2012, 'Preventive interventions for ADHD: A neurodevelopmental perspective', Neurotherapeutics 9(3), 531-541. https://doi.org/10.1007/s13311-012-0123-z

Instanes, J.T., Halmøy, A., Engeland, A., Haavik, J., Furu, K. \& Klungsøyr, K., 2017, 'Attention-deficit/hyperactivity disorder in offspring of mothers with inflammatory and immune system diseases', Biological Psychiatry 81(5), 452-459. https://doi. org/10.1016/j.biopsych.2015.11.024

Jerome, L., Gordon, M. \& Hustler, P., 1994, 'A comparison of American and Canadian teachers' knowledge and attitudes towards attention deficit hyperactivity disorde (ADHD)', The Canadian Journal of Psychiatry 39(9), 563-567. https://doi. org/10.1177/070674379403900909

Kaur, G. \& Nitakumari, K., 2018, 'A Descriptive Study to assess the knowledge regarding ADHD among primary school teachers in selected schools of district Mohali with view to develop informational booklet', Asian Journal of Nursing Education and Research 8(3), 399-402. https://doi.org/10.5958/2349-2996.2018.00082.4

Kellner, R., Houghton, S. \& Douglas, G., 2003, 'Peer-related personal experiences of children with attention-deficit/hyperactivity disorder with and without comorbid learning disabilities', International Journal of Disability, Development and Education 50(2), 119-136. https://doi.org/10.1080/1034912032000089639

Kern, A., Amod, Z., Seabi, J. \& Vorster, A., 2015, 'South African foundation phase teachers' perceptions of ADHD at private and public schools', International Journal of Environmental Research and Public Health 12(3), 3042-3059. https:// doi.org/10.3390/ijerph120303042

Kissgen, R. \& Franke, S., 2016, 'ADHS im Fokus der Bindungsforschung', Neuropsychiatrie 30(2), 63-68. https://doi.org/10.1007/s40211-016-0182-1

Kos, J., 2008, What do primary school teachers know, think and do about ADHD? Thesis, RMIT University, Melbourne.

Kos, J., Richdale, A. \& Hay, D., 2006, 'Children with attention deficit hyperactivity disorder and their teachers: A review of the literature', International Journal of Disability, Development and Education 53(2), 147-160. https://doi. org/10.1080/10349120600716125

Kosidou, K., Dalman, C., Widman, L., Arver, S., Lee, B.K., Magnusson, C. et al., 2017 'Maternal polycystic ovary syndrome and risk for attention-deficit/hyperactivity 'Misorder in the offspring', Biological Psychiatry 82(9), 651-659. https://doi. disorder in the offspring, Biological
org/10.1016/j.biopsych.2016.09.022

Lasisi, D., Ani, C., Lasebikan, V., Sheikh, L. \& Omigbodun, O., 2017, 'Effect of attentiondeficit-hyperactivity-disorder training program on the knowledge and attitudes of primary school teachers in Kaduna, North West Nigeria', Child and Adolescent primary school teachers in Kaduna, North West Nigeria, Child and Adolescent Psychiatry

Layton, T.J., Barnett, M.L., Hicks, T.R. \& Jena, A.B., 2018, 'Attention deficit-hyperactivity disorder and month of school enrollment', New England Journal of Medicine 379(22), 2122-2130. https://doi.org/10.1056/NEJMoa1806828

Lazarus, K.J., 2013, The knowledge and perceptions of attention deficit hyperactivity disorder held by foundation phase educators in a Township in Gauteng, Thesis, University of the Witwatersrand, Johannesburg.

Mannuzza, S. \& Klein, R.G., 2000, 'Long-term prognosis in attention-deficit/ hyperactivity disorder', Child and Adolescent Psychiatric Clinics 9(3), 711-726.

Mazzone, L., Postorino, V., Reale, L., Guarnera, M., Mannino, V., Armando, M. et al., 2013, 'Self-esteem evaluation in children and adolescents suffering from ADHD', Clinical Practice and Epidemiology in Mental Health 9(1), 96. https://doi org/10.2174/1745017901309010096

Miller, M. \& Hinshaw, S.P., 2015, 'Attention-deficit/hyperactivity disorder', Encyclopedia of Mental Health: Second Edition 387(1), 116-123. https://doi. org/10.1016/B978-0-12-397045-9.00229-9
Modesto, T., Tiemeier, H., Peeters, R.P., Jaddoe, V.W.V., Hofman, A., Verhulst, F.C. et al., 2015, 'Maternal mild thyroid hormone insufficiency in early pregnancy and attention-deficit/hyperactivity disorder symptoms in children', JAMA Pediatrics 169(9), 838-845. https://doi.org/10.1001/jamapediatrics.2015.0498

Nel, N., Nel, M. \& Hugo, A., 2013, Learner support in a diverse classroom: A guide for foundation, intermediate and senior phase teachers of language and mathematics, Van Schaik Publishers, Pretoria.

Norvilitis, J.M. \& Fang, P., 2005, 'Perceptions of ADHD in China and the United States: A preliminary study', Journal of Attention Disorders 9(2), 413-424. https://doi. org $/ 10.1177 / 1087054705281123$

Ntuli, B.N., 2014, Attitudes of educators towards children with attention deficit hyperactivity disorder, University of Zululand, Richards Bay.

Ohan, J.L., Cormier, N., Hepp, S.L., Visser, T.A.W. \& Strain, M.C., 2008, 'Does knowledge about attention-deficit/hyperactivity disorder impact teachers' reported behaviors and perceptions?', School Psychology Quarterly 23(3), 436. https://doi. org/10.1037/1045-3830.23.3.436

Otasowie, J., Castells, X., Ehimare, U.P. \& Smith, C.H., 2014, 'Tricyclic antidepressants for attention deficit hyperactivity disorder (ADHD) in children and adolescents', Cochrane Database of Systematic Reviews 9, CD006997. https://doi. org/10.1002/14651858.CD006997.pub2

Perold, H., Louw, C. \& Kleynhans, S., 2010, 'Primary school teachers' knowledge and misperceptions of attention deficit hyperactivity disorder (ADHD)', South African Journal of Education 30(3), 457-473.

Pfiffner, L.J., Barkley, R.A. \& Du Paul, G.J., 2006, 'Treatment of ADHD in school settings', in R.A. Barkley (ed.), Attention deficit hyperactivity disorder: A handbook for diagnosis and treatment, pp. 547-589, vol. 3, Guilford Press, New York, NY.

Pisecco, S., Huzinec, C. \& Curtis, D., 2001, 'The effect of child characteristics on teachers' acceptability of classroom-based behavioral strategies and psychostimulant medication for the treatment of ADHD', Journal of Clinical Child Psychology 30(3), 413-421. https://doi.org/10.1207/S15374424JCCP3003_12

Reichenberg, L.W. \& Seligman, L., 2016, Selecting effective treatments: A comprehensive, systematic guide to treating mental disorders, John Wiley \& Sons, New Jersey.

Sax, L. \& Kautz, K.J., 2003, 'Who first suggests the diagnosis of attention-deficit/ hyperactivity disorder?', The Annals of Family Medicine 1(3), 171-174. https:// doi.org/10.1370/afm.3

Sciutto, M.J., Terjesen, M.D., Kučerová, A., Michalová, Z., Schmiedeler, S., Antonopoulou, K. et al., 2016, 'Cross-national comparisons of teachers' knowledge and misconceptions of ADHD', International Perspectives in Psychology: Research, Practice, Consultation 5(1), 34.

Sonuga-Barke, E.J.S., Brandeis, D., Cortese, S., Daley, D., Ferrin, M., Holtmann, M. et al., 2013, 'Nonpharmacological interventions for ADHD: Systematic review and meta-analyses of randomized controlled trials of dietary and psychological treatments', American Journal of Psychiatry 170(3), 275-289. https://doi. org/10.1176/appi.ajp.2012.12070991

Taylor, E., Döpfner, M., Sergeant, J., Asherson, P., Banaschewski, T., Buitelaar, J. et al., 2004, 'European clinical guidelines for hyperkinetic disorder-first upgrade', European Child \& Adolescent Psychiatry 13(1), i7-i30. https://doi.org/10.1007/ s00787-004-1002-x

Thapar, A., Cooper, M., Eyre, O. \& Langley, K., 2013, 'Practitioner review: What have we learnt about the causes of ADHD?', Journal of Child Psychology and Psychiatry and Allied Disciplines 54(1), 3-16. https://doi.org/10.1111/j.1469-7610.2012.02611.x

Topkin, B., 2013, An examination of primary school teachers' knowledge of the symptoms and management of children diagnosed with ADHD in their classrooms, symptoms and management of Children diagnos
University of the Western Cape, Cape Town.

Topkin, B., Roman, N.V. \& Mwaba, K., 2015, 'Attention Deficit Disorder (ADHD): Primary school teachers' knowledge of symptoms, treatment and managing classroom behaviour', South African Journal of Education 35(2), 1-8. https://doi. org/10.15700/saje.v35n2a988

Training, P.S. \& Bolat, H., 2017, 'Attention-deficit/hyperactivity disorder and very preterm/very low birth weight: A meta-analysis', Pediatrics 141(1), e20171645. https://doi.org/10.1542/peds.2017-1645

Vereb, R.L. \& DiPerna, J.C., 2004, 'Teachers' knowledge of ADHD, treatments for ADHD, and treatment acceptability: An initial investigation', School Psychology Review 33(3), 421-428. https://doi.org/10.1080/02796015.2004.12086259

Vizzini, L., Popovic, M., Zugna, D., Vitiello, B., Trevisan, M., Pizzi, C. et al., 2019, 'Maternal anxiety, depression and sleep disorders before and during pregnancy, and preschool ADHD symptoms in the NINFEA birth cohort study', Epidemiology and Psychiatric Sciences 28(5), 521-531. https://doi.org/10.1017/ S2045796018000185

West, J., Taylor, M., Houghton, S. \& Hudyma, S., 2005, 'A comparison of teachers and parents knowledge and beliefs about attention-deficit/hyperactivity disorder (ADHD)', School Psychology International 26(2), 192-209. https://doi org/10.1177/0143034305052913

Willcutt, E.G., 2012, 'The prevalence of DSM-IV attention-deficit/hyperactivity disorder: A meta-analytic review', Neurotherapeutics 9(3), 490-499. https://doi. org/10.1007/s13311-012-0135-8 